\title{
Strength of tensed and compressed concrete segments in crack spacing under short-term dynamic load
}

\author{
Zaur Galyautdinov ${ }^{1, *}$ \\ ${ }^{1}$ Tomsk State University of Architecture and Building, 634003 Tomsk, Russia
}

\begin{abstract}
Formation of model describing dynamic straining of reinforced concrete requires taking into account the basic aspects influencing the stress-strain state of structures. Strength of concrete segments in crack spacing is one of the crucial aspects that affect general strain behavior of reinforced concrete. Experimental results demonstrate significant change in strength of tensed and compressed concrete segments in crack spacing both under static and under dynamic loading. In this case, strength depends on tensile strain level and the slope angle of rebars towards the cracks direction. Existing theoretical and experimental studies estimate strength of concrete segments in crack spacing under static loading. The present work presents results of experimental and theoretical studies of dynamic strength of plates between cracks subjected to compression-tension. Experimental data was analyzed statistically; the dependences were suggested to describe dynamic strength of concrete segments depending on tensile strain level and slope angle of rebars to cracks direction.
\end{abstract}

\section{Introduction}

Complexity of modern structures, as well as the variety of aspects affecting their operation requires comprehensive approach applied to the developed models of dynamic analysis of reinforced concrete structures. The existing reinforced concrete models enable to take into account basic peculiar features of concrete and reinforcement straining at all stages of structure performance [1-8]. Along with that, a number of issues still require additional study, particularly in the conditions of high-velocity impact.

It is known that in flat-strained reinforced concrete structures cracks occur in the areas of principal tensile stresses; and they can be generally cross-oriented towards the bars of reinforcement mesh. After crack occurrence concrete cannot sustain tensile stresses within the direction which is perpendicular to the crack direction, therefore all tensile stresses within this direction are transmitted through the reinforcement. Stresses in orthogonal direction are withstood by concrete segments in crack spacing.

Strength of such concrete segments under static loading was studied by Russian and foreign scientists [1, 9-12]; a review of the mentioned works was given in [13]. Experimental studies provide the data on influence of the samples strain level in the

\footnotetext{
*Corresponding author: gazr@yandex.ru
} 
direction which is perpendicular to the crack and the influence of the slope angle of rebars towards the cracks direction. Authors suggested equations for calculation of strength of concrete segments between cracks under static loading that take into account the aspects mentioned above [13]. However, peculiar features of strain of concrete segments in crack spacing under intensive dynamic loading have not been previously studied.

The present paper aims to study strength of concrete segments in crack spacing under short-term dynamic loading.

\section{Materials and methods}

Experimental and theoretical analysis of strain of tensed and compressed concrete segments in crack spacing under short-term dynamic loading was conducted. Studies considered both influence of strain level of the sample perpendicular to the crack as well as the slope angle of rebars towards the cracks direction. Reinforced concrete plates with fixed cracks were used for experimental studies. The total amount of tested samples was 72, including: 23 samples under $\alpha=90^{\circ} ; 28$ samples under $\alpha=45^{\circ}$ and 21 sample under $\alpha=30^{\circ}$. Celluloid fillings were mounted in all the samples while placement of concrete, which during the experiment lead to formation of cracks separating concrete blocks. Rebars were placed inclined to the crack. The slope angle of rebars to the crack $\alpha$ was accepted as equal to $90^{\circ}, 45^{\circ}$ and $30^{\circ}$. Samples with $\alpha=30^{\circ}$ and $\alpha=45^{\circ}$ were mounted with metal plates (Pos. 2, Fig. 1) along the exposed face which prevented mutual displacement of rebars. Figure 1 shows the basic sizes and reinforcement schemes of samples.

\section{Experimental studies}

Experimental samples were made from heavy weight concrete, of B15 brand. Material used for reinforcement mesh was rebars of A400 brand, $8 \mathrm{~mm}$ in diameter.

Simultaneously with these samples 6 reference cubes were made with the edge size of $100 \mathrm{~mm}$, and 6 prisms $100 \times 100 \times 400 \mathrm{~mm}$ to define strength and strain properties of concrete. All cubes were subjected to static loading. Prisms were tested under static (3 prisms) and short-term dynamic (3 prisms) loading. Dynamic testing of prisms was conducted under strain rate $\dot{\varepsilon}_{b}$ which was close to the strain rate of reference samples, which allowed defining the ratio of dynamic strength of concrete segments in crack spacing to dynamic strength of standard prisms.

During the experiment loading was applied to the sample in two mutually orthogonal directions. The sample was subject to tension within one direction and compression within another (Fig. 2). Tensile stresses were completely transmitted through the reinforcement. Compressive stresses were transmitted through the concrete blocks between cracks (Fig. 2). Testing was conducted within two stages, first the tension was applied up to the required level, and then it was followed by compression up to complete failure. Tension was marked by crack occurrence dividing the sample into three concrete blocks connected with each other by reinforcement. 
a)

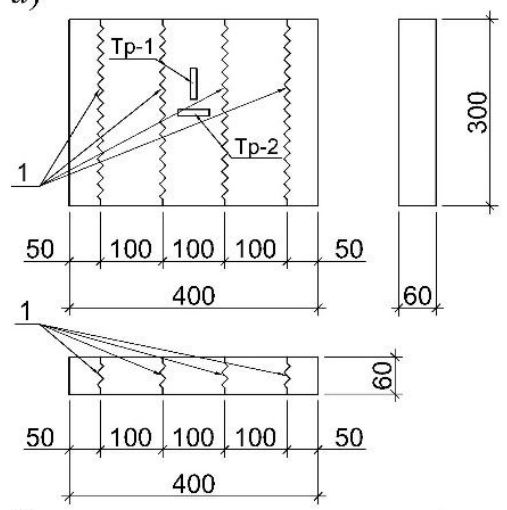

b)

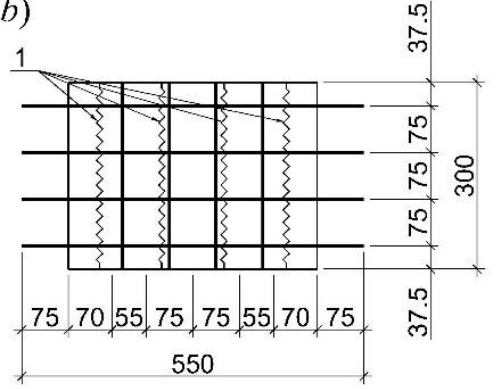

c)
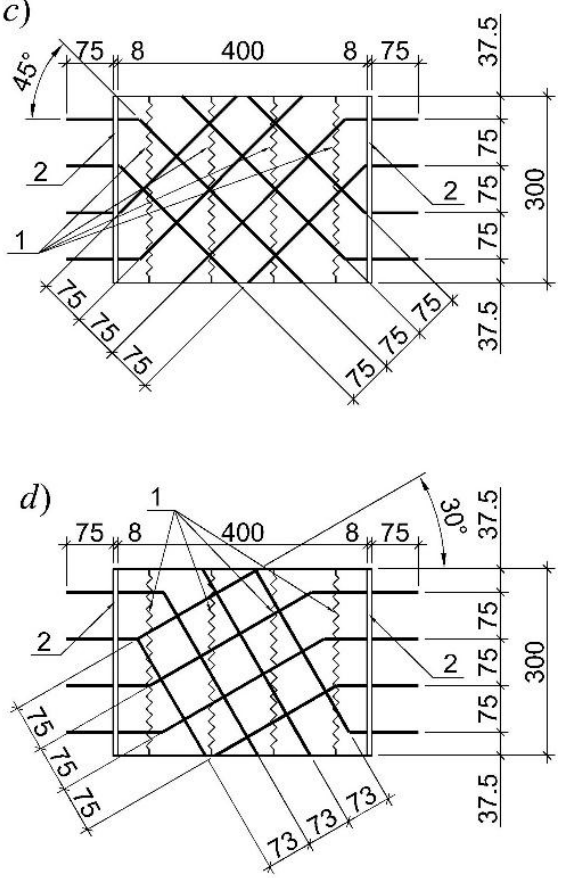

Fig. 1. General view of the samples and placement of strain-gauge sensors on concrete $(a)$ and schemes of samples reinforcement under different slope angles of rebars to the cracks $(b, c, d): 1-$ cracks; 2 - metal plates.

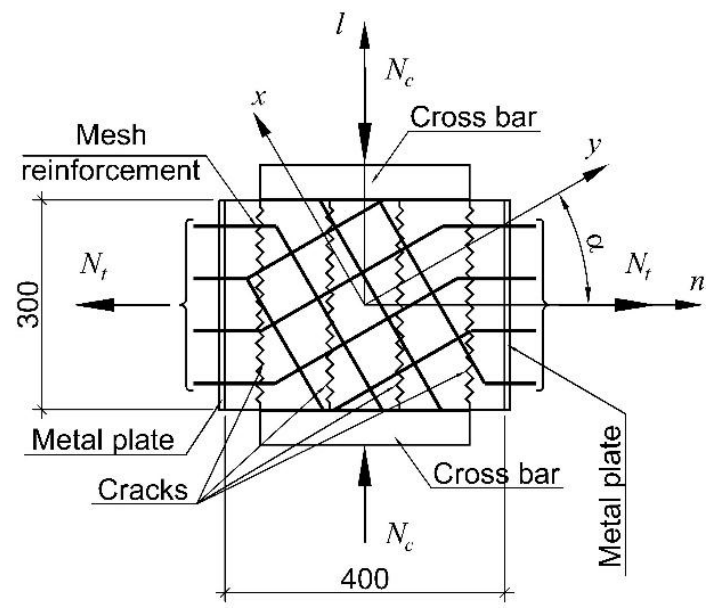

Fig. 2. Testing configuration.

Tensile loading was applied by means of hydraulic jack. Dynamic compressive stresses were provided by falling weight energy. The height of falling weight and its size was selected under condition of elasto-plastic strain of structure up to complete depletion of load-bearing capacity by single loading. 


\section{Results}

Figure 3 demonstrates fracture patterns of samples with different angles $\alpha$. As can be seen from Figure 3, with almost the same level of tensile strain $\left(\varepsilon_{l}=111.1 \times 10^{-5} \ldots 184.7 \times 10^{-5}\right.$ u.t.s. $)$ for samples with $\alpha=90^{\circ}$ fracture of a concrete segment is local, however for samples with $\alpha=30^{\circ}$ and $\alpha=45^{\circ}$ one can observe almost complete fracture of the concrete segment. Ultimate fracture load for samples was $106.65 \mathrm{kN}\left(\alpha=90^{\circ}\right), 102.9 \mathrm{kN}\left(\alpha=30^{\circ}\right)$ and $89.89 \mathrm{kN}\left(\alpha=45^{\circ}\right)$.

a)

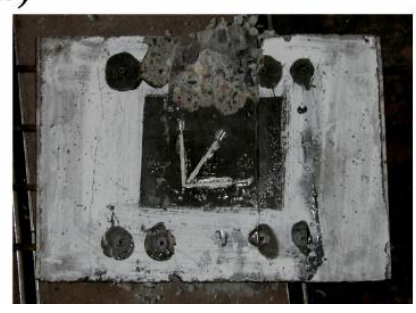

b)

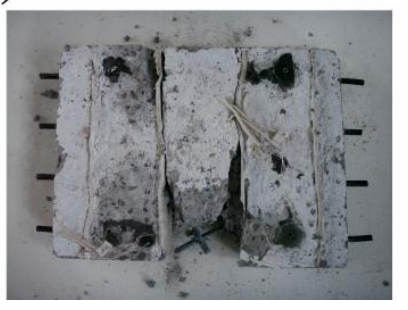

c)

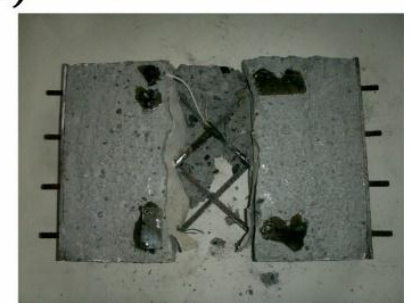

Fig. 3. Fracture patterns of samples: $a$ - under $\alpha=90^{\circ}$ and $\varepsilon_{l}=184.7 \times 10^{-5}$ u.t.s. ; $b$-under $\alpha=30^{\circ}$ and $\varepsilon_{l}=152.41 \times 10^{-5}$ u.t.s. ; $c$-under $\alpha=45^{\circ}$ and $\varepsilon_{l}=111 \times 10^{-5}$ u.t.s.

Figure 4 shows the data on strength of concrete segments in crack spacing under different strain level of samples $\varepsilon_{l}$, for the accepted slope angles of rebars. It can be seen from the study that the strength of such concrete segments decreases with increase of the strain level perpendicular to the crack $\varepsilon_{l}$ for all values of slope angle of rebars to the crack $\alpha$. Moreover, for $\alpha=30^{\circ}$ and $\alpha=45^{\circ}$ larger decrease of strength is observed. This is conditioned by fracture of concrete structure and adhesion of concrete segments in crack spacing with reinforcement under tension. The higher the strain level $\varepsilon_{l}$ is, the more materials structure is fractured.

Experimental studies of strength of concrete segments in crack spacing enabled to estimate qualitatively the influence of the investigated aspects. Quantitative evaluation of the strain influence $\varepsilon_{l}$ under different slope angle of rebars $\alpha$ on the strength of concrete segments in crack spacing was performed using mathematical statistics methods [14].

\section{Theoretical studies}

The obtained experimental data testify on the nonlinear change of strength of concrete segments depending on the strain level $\varepsilon_{l}$ (Fig. 4, 5a). The largest strength decrease was observed at the initial stage by strain up to $\varepsilon_{l}=400 \times 10^{-5}$ u.t.s., after that the intensity of strength decrease went down. In this regard, at the initial stage the data was transformed to the linear view, it was followed by the assessment of data samples including screening of gross errors and conformance inspection of strength distribution in concrete segments in crack spacing to the normal distribution law. Results for samples with $\alpha=30^{\circ}$ are presented in Figure 5. Screening of gross errors was conducted with the aid of Student's tdistribution. Checking data distribution in accordance with the normal distribution law performed based on Kolmogorov-Smirnov and Shapiro-Wilk criteria showed their correspondence to the normal distribution law (Fig. $5 c, d$ ). 


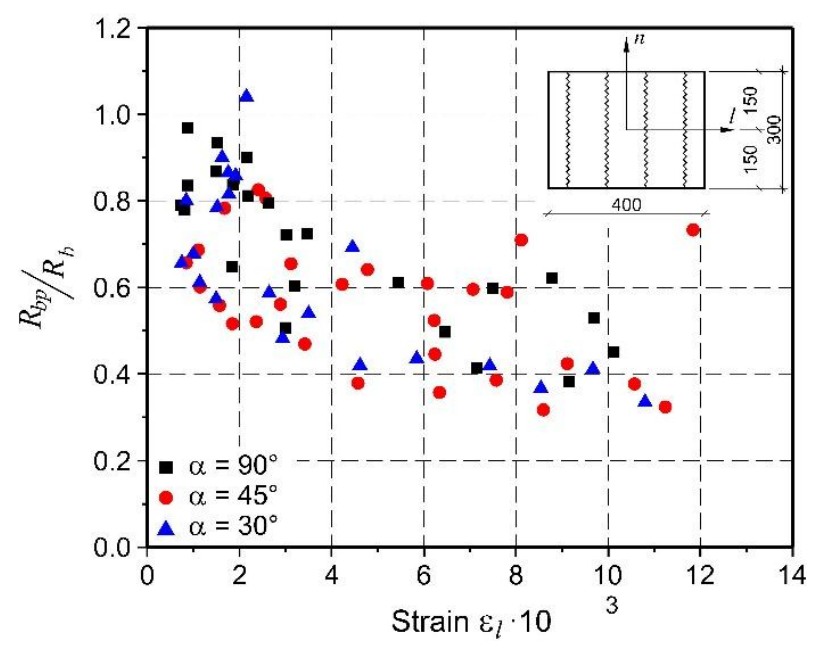

Fig. 4. Change of strength of concrete segments in crack spacing under short-term dynamic loading depending on the slope angle and strain level.

The calculated correlation coefficients characterizing the dependence of strength and strain level $\varepsilon_{l}$, was equal: to 0.804 for $\alpha=90^{\circ}$; to 0.652 for $\alpha=45^{\circ}$; to 0.811 for $\alpha=30^{\circ}$. This testifies on the average and high degree of connection of the values under study.

Regression analysis was conducted using methodology described in [14]. Based on the least square method the regression equations were derived, which can be given as follows after inverse transformation:

- $\quad$ for $\alpha=90^{\circ}$

$$
\frac{R_{b p d}}{R_{b d}}=\frac{1}{\left(0.7043+0.1639 \cdot \lg \left(\varepsilon_{l}\right)\right)^{4}},
$$

- $\quad$ for $\alpha=45^{\circ}$

$$
\frac{R_{b p d}}{R_{b d}}=\frac{1}{\left(0.7529+0.1639 \cdot \lg \left(\varepsilon_{l}\right)\right)^{4}},
$$

- $\quad$ for $\alpha=30^{\circ}$

$$
\frac{R_{b p d}}{R_{b d}}=\frac{1}{\left(0.65595+0.2023 \cdot \lg \left(\varepsilon_{l}\right)\right)^{4}} .
$$


a)

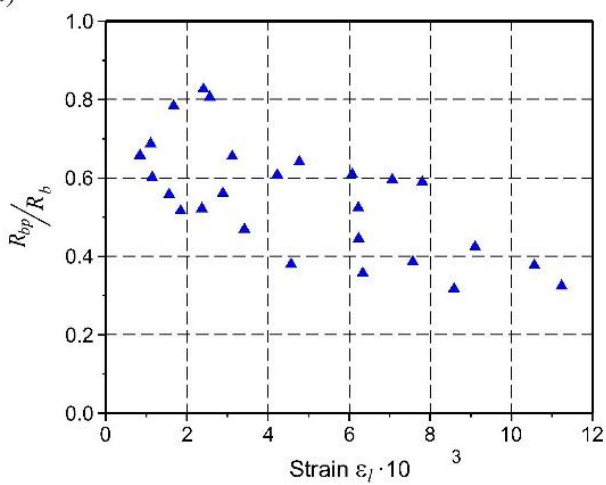

c)

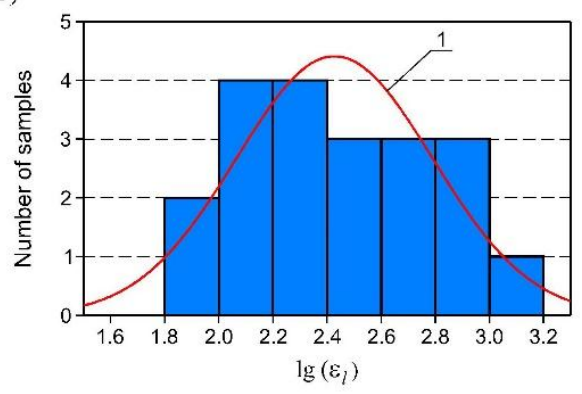

b)

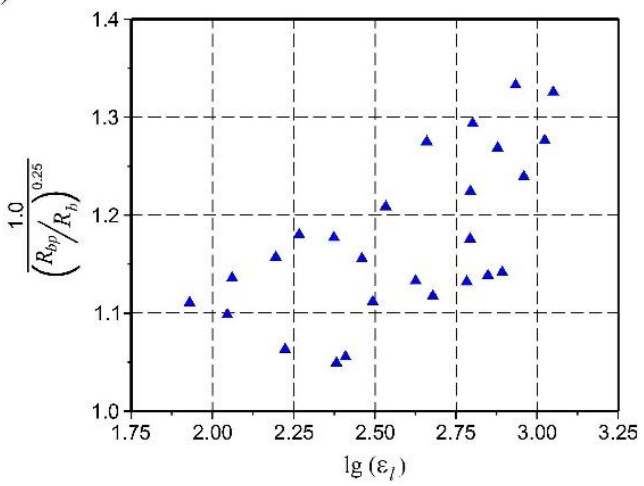

d)

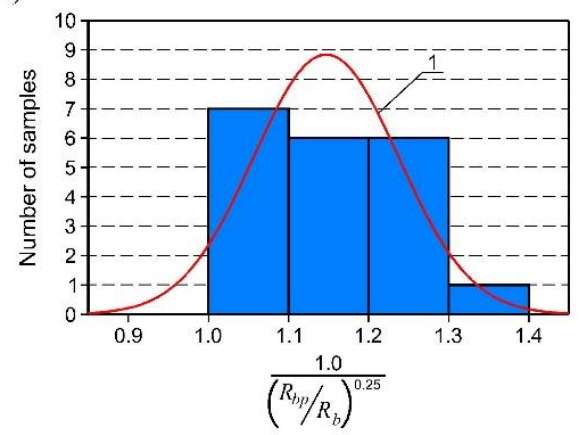

Fig. 5. Change of strength in concrete segments in crack spacing under short-term dynamic loading for $\alpha=30^{\circ}(a, b)$ and experimental and theoretical distribution of the considered values after their transformation to linear view $(\mathrm{c}, d)$ : 1 - normal theoretical distribution.

To estimate significance of the obtained equations Fisher's criteria was used which has the following values: $F_{(1,21)}=38.523$ for $\alpha=90^{\circ} ; F_{(1,24)}=17.732$ for $\alpha=45^{\circ} ; F_{(1,18)}=34.655$ for $\alpha=30^{\circ}$. The obtained values were higher than the tabular ones corresponding to $5 \%$ probability of the correspondently equal $F_{(1,21)}^{\mathrm{T}}=4.3248, F_{(1,24)}^{\mathrm{T}}=4.2597$ and $F_{(1,18)}^{\mathrm{T}}=4.4139$. Thus, the given dependences allow defining dynamic strength of concrete segments in crack spacing with confidence probability of 0.95 , as stated in regulatory documents.

Analysis of the obtained theoretical dependences given in Figure 6 shows that the strength of concrete segments of samples whose rebars have slope angle $\alpha=30^{\circ}$ and $\alpha=45^{\circ}$, is significantly lower than the strength for $\alpha=90^{\circ}$. Along with that, the strength values for samples with $\alpha=30^{\circ}$ and $\alpha=45^{\circ}$ are comparable. This nature of strength variation in concrete segments is conditioned by existence of additional stresses in concrete samples with $\alpha=30^{\circ}$ and $\alpha=45^{\circ}$ which occur during strain of reinforcement mesh, and do not occur in samples with $\alpha=90^{\circ}$. 


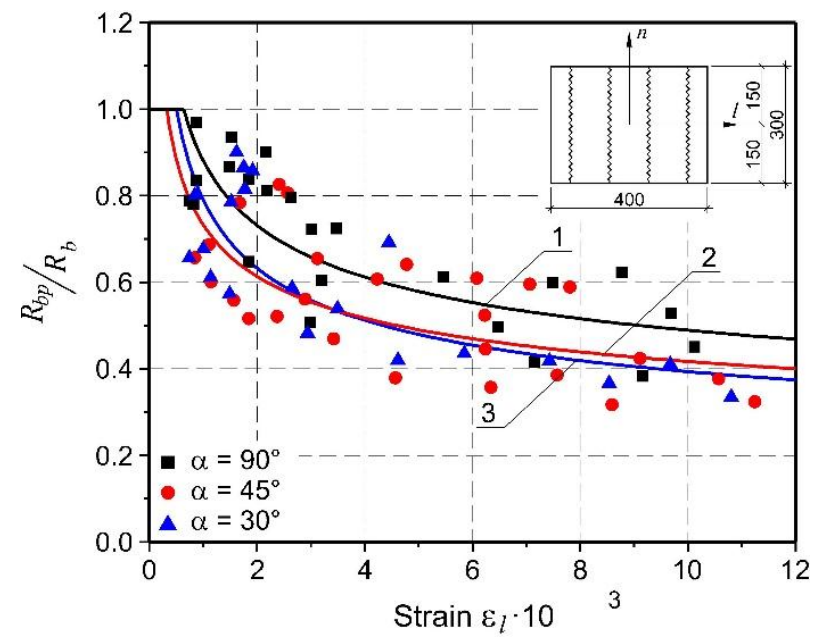

Fig. 6. Experimental and theoretical change of strength of concrete segments in crack spacing under short-term dynamic loading: 1 - according to equation (1); 2 - according to equation (2); 3 according to equation (3); $\mathbf{\square}, \bullet, \mathbf{\Delta}$ - experimental data.

\section{Conclusion}

Experimental and theoretical studies revealed significant influence of the strain level of samples in the direction perpendicular to the crack $\varepsilon_{l}$ and the slope angle of rebars to the cracks direction $\alpha$ on the strength of concrete segments in crack spacing. It should be noted that the elements with angles $\alpha$ that differ from $90^{\circ}$ demonstrate larger strength decrease in concrete segments compared to the elements with $\alpha=90^{\circ}$ within the whole range of tension strain $\varepsilon_{l}$.

Resulting from data processing obtained during experimental study dependences were suggested to define strength of concrete segments in crack spacing. Assessment of the given equations testifies on the sufficient reliability of the calculated values of concrete segments strength. The obtained results enable to clarify the model of dynamic straining of reinforced concrete; application of this model in calculations will allow obtaining more consistent results characterizing straining of reinforced concrete structures under intensive dynamic loading. Further step of the presented studies will be assessment of deformation property of concrete segments in crack spacing.

\section{References}

1. N.I. Karpenko, Obshhie modeli mehaniki zhelezobetona [General models of reinforced concrete mechanics] (Strojizdat, Moscow, 1996) (in Russian)

2. N.I. Karpenko, Structural Mechanics and Analysis of Constructions, 1, 28-32 (1984) (in Russian)

3. J. Jones, C. Wua, D.J. Oehlers, A.S. Whittaker, W. Sunc, S. Marksa, R. Coppola, Engineering Structures, 31, 2825-2832 (2009)

4. B. Chiaia, O. Kumpyak, L. Placidi, V. Maksimov, Engineering Structures, 96, 88-99 (2015)

5. Z.R. Galyautdinov, News of higher educational institutions. Construction, 10, 93-98 (2010) (in Russian)

6. X. Chen, S. Wu, J. Zhou, Construction and Building Materials, 47, 419 - 430 (2013) 
7. F.R. Barrales, Development of a nonlinear quadrilateral layered membrane element with drilling degrees of freedom and a nonlinear quadrilateral thin flat layered shell element for the modeling of reinforced concrete walls, Ph.D. thesis (University of Southern California, 2012)

8. O.G. Kumpyak, D.N. Kokorin, Vestnik of TSUAB, 4, 101 - 112 (2015) (in Russian)

9. A.F. Yaremenko, Prikladnaja teorija dlitel'nogo deformirovanija i soprotivlenija ploskih zhelezobetonnyh elementov [Applied theory of long-term deformation and resistance of flat reinforced concrete elements], doctoral thesis (Odessa, 1987) (in Russian)

10. A. Belarbi, L.-X. Zhang, T.T.C. Hsu, Sociedad Mexicana de Ingenieria Sismica in Eleventh World Conference on Earthquake Engineering, 1-8 (Acapulco, Mexico, June 23-28, 1996)

11. B.Y. Bahn, T.T.C. Hsu, ACI Structural Journal, 95, 178-193 (1998)

12. F.J. Vecchio, M.P. Collins, ACI Journal, 83, 219-231 (1986)

13. O.G. Kumpyak, Z.R. Galyautdinov, D.N. Kokorin, Prochnost' $i$ deformativnost' zhelezobetonnyh konstrukcij na podatlivyh oporah pri kratkovremennom dinamicheskom nagruzhenii [Strength and deformability of reinforced concrete structures on yielding supports under short-term dynamic load] (TSUAB Publ., Tomsk, 2016)

14. E.N. L'vovskij, Statisticheskie metody postroenija empiricheskih formul [Statistical methods of empirical formulas] (Vysshaya Shkola Publishers, Moscow, 1988) 